\title{
Maternal minimum dietary diversity and associated factors among pregnant women, Southwest Ethiopia, 2021
}

\author{
Abel Girma Tilahun ${ }^{*}$ and Abebaw Molla Kebede
}

\begin{abstract}
Background: Inadequate dietary diversity intake during pregnancy increases risks of intrauterine growth restriction, abortion, low birth weight, preterm birth, prenatal and infant mortality,and morbidity and has long-lasting health impacts. Dietary diversity during pregnancy promotes the health status of the mother and her fetus. This study aimed to assess the magnitude of minimum dietary diversity and associated factors among pregnant women attending antenatal care.
\end{abstract}

Methods: A facility-based cross-sectional study was conducted among 274 pregnant women who attended antenatal care at Wacha primary hospital from January to February 2021. A systematic sampling method was used to select the study participants. The data were collected through face-to-face interviews using a structured and semi-structured questionnaire. Bivariate logistic regression was done to identify factors associated with maternal dietary diversity. Finally, multivariate logistic regression was done, and variables that showed $P$ values of $<0.05$ were considered statistically significant.

Result: The magnitude of minimum dietary diversity was $51 \%(95 \% \mathrm{Cl}: 44.5,56.7)$. The mean ( \pm SD) minimum dietary diversity score was $4.5( \pm 1.268)$ with a minimum of 1 anda maximum of 8 food groups consumed out of ten food groups. Age fewer than 25 years (AOR 4.649; 95\% Cl; 1.404, 15.396), and the age group between 25 to 34 years (AOR 3.624; 95\% Cl: 1.315, 10.269), husband age group of 26 to 34 years (AOR 2.238; 95\% Cl; 1.028,4.873), and 35 to 44 years (AOR 3.555; 95\% Cl; 1.228,10.292) and nutrition awareness of women (AOR 2.182; 95\% Cl; 1.243, 3.829) were significantly associated with minimum dietary diversity.

Conclusion: The consumption of minimum dietary diversity of the pregnant mothers was found to be low. Women aged less than 25 and age between 25 to 34 years, husband's age between 26 to 34 and 35 to 44 years, and nutrition awareness were the factors significantly associated with minimum dietary diversity. Therefore, providing nutrition education and counseling service warranted to promote maternal dietary diversity.

Keywords: Dietary diversity, Pregnant women, Kaffa zone, Southwest Ethiopia

\footnotetext{
*Correspondence: abeloo405@mtu.edu.et; abeloo405@gmail.com Department of Reproductive Health and Human Nutrition, College of Medicine and Health Science, Mizan-Tepi University, Mizan-Aman, Ethiopia
} 


\section{Background}

Poor dietary diversity is the major public health concern for pregnant women in resource-poor environments all over the world [1,2]. Dietary diversity is the number of food groups consumed across and within food groups over a given reference period [1,3]. It is a key dimension of diet quality which is defined as a diet that delivers adequate amounts of selected micronutrients, to meet the needs of women of reproductive age and the indicators of nutritional adequacy [1, 3]. Pregnancy by itself places a further burden on women's nutritional requirement which increase the nutrient needs to meet the demands of both the mother and the developing fetus [4]. Dietary diversity in pregnant women is used to reduce maternal mortality and morbidity and it is also a foundation to the developing fetus' growth and reduced perinatal outcome complications $[5,6]$. In contrast suboptimal diets of pregnant women further impacts the health of the mother, the developing fetus, and the newborn [7]. Furthermore, inadequate dietary diversity intake during pregnancy results in increased risks such as maternal anemia, intrauterine growth restriction (IUGR), abortion, low birth weight (LBW), preterm birth, prenatal and infant mortality, and morbidity and increase the risk of chronic disease in the later period of life [8-13].

Poor dietary quality is one of the leading causes of premature death and diseases globally [14]. Maternal inadequate dietary diversity contributed to $7 \%$ of the global disease burden and at least one-fifth of maternal deaths and poor maternal outcomes [15, 16] and while one million neonates die on the first day and in the first week of life, as linked with increasing trends in maternal anemia, mortality, and adverse birth outcomes [17]. In Sub-Saharan Africa, the burden of nutritional deficiency among pregnant women is still high [18-20]. Micronutrient deficiency and maternal undernutrition can affect pregnancy birth outcomes, increase maternal mortality and reduce economic outcomes [9, 21-23]. In Ethiopia, the maternal mortality ratio is 401 per 100,000 live birth and while the neonatal mortality rate is 28 per 1000 live births [23] and while about $22 \%$ of women are thin, $24 \%$ anemic and $8 \%$ of women are obese [24] and 23 and $15 \%$ of women reproductive age in South Nation, Nationality and People Region (SNNPR) of Ethiopia are anemic and thin due to inadequate dietary intake respectively [25]. In resource-poor environments across the globe, there are dominant plant-based staple foods and diets that lack vegetable, fruits, and animal-source foods [1]. There is low minimum dietary diversity in Ethiopia among pregnant women [26]. Only 47\% of pregnant women had to meet minimum dietary diversity in Ethiopia at the national level [27] and 28\% of pregnant women had to meet adequate dietary diversity in the SNNPR of Ethiopia [22] where on an average 3.7 of 10 food groups were eaten by pregnant women [23].

To adequately provide the required nutrients and to reduce maternal malnutrition one of the bestrecommended strategies among pregnant women is dietary diversification through increasing food group consumption in daily diet [28]. The government of Ethiopia has developed the second phase National Nutrition Program (NNP II 2016-2020), which focuses on the critical 1000-day window - from pregnancy through the first two years of life - to address malnutrition and with one of its program objectives of improving pregnant and lactating women's nutrition through comprehensive and routine nutritional assessments and counseling services [23].. The main identified factors for poor dietary diversity in developing countries were socio-demographic and economic factors, food insecurity, lack of nutrition counseling and environmental factors [17, 27, 29-35]. Identifying and addressing the possible factors associated with maternal dietary diversity has a significant contribution to enhancing the nutritional and health status of both mother and her fetus. The finding of this study will help policymakers and planners to set their target with interventions in the study area and might be a means of achieving the sustainable development goals (SDGs) in an integrated manner. However, there is a lack of information in this study area. Therefore, this study was aimed to assess maternal dietary diversity and associated factors among pregnant women attending antenatal care (ANC) at Wacha primary hospital, southwest asia Ethiopia.

\section{Methods}

\section{Study area}

The study was conducted at Wacha primary hospital which was established in 2005. It is found in Chena town, Kaffa Zone, Southwest Ethiopia which is located $541 \mathrm{~km}$ far from Addis Ababa, the capital city of Ethiopia and it is the only hospital in Chena district. The hospital has been giving health services for the total population of 30,891 people in its catchment area with different four major departments including medical, pediatrics, surgical, and obstetrics, and gynecology. It also provides outpatient service, ophthalmology, emergency, antiretroviral Therapy (ART) clinic, and ANC clinic. There were a total of 723 pregnant women who had attended ANC in 2020/21 and on average around 30-40 followers have been attended ANC clinic every day at Wacha primary hospital.

\section{Study design and study period}

A facility-based cross-sectional study was conducted from January to February 2021. 


\section{Source population}

All pregnant women attended the ANC clinic at Wacha primary hospital, Kaffa zone.

\section{Study population}

All randomly selected pregnant women attending ANC clinic at Wacha primary hospital from 16 weeks gestational age were included in the sample.

\section{Sample size determination}

The required sample size was determined using single population proportion formula based on the assumption of high minimum dietary diversity of $55.2 \%$ in Bale zone, Ethiopia [33], 5\% margin of error, 95\% of Confidence Interval $(\mathrm{CI}), 10 \%$ of non-response rate, and by using the correction formula since the target population of the study area was below 10,000 . Then the final sample sizes 274 of pregnant women were included.

\section{Sampling method}

The study participants were selected by using a systematic random sampling technique. The sampling interval was determined by calculating monthly average attendance for ANC follow-up divided by the required sample size, and then, the first study participant was selected randomly and then every third pregnant woman was included.

\section{Inclusion criteria}

Pregnant women with greater than 16 week's gestational age and who lived in the study area for at least one year were included in the study.

\section{Exclusion criteria}

Pregnant women who were unable to speak\&/hear and who have seriously ill during data collection.

\section{Study variables}

The dependent variable of this study was dietary diversity status, and independent variables like age, marital status, occupation, residence, educational status, family size, household head, nutrition awareness of women, maternal health status, husband support, income, having mobile phone, radio and bank account, garden, water source, availability of latrine, marketing, and household food security and nutritional status of pregnant women.

\section{Data collection technique}

The data were collected through face-to-face interviews using pretested structured and semi-structured questionnaires adapted from different kinds of literature $[2,33,36]$. The data were collected by welltrained Nurse professionals. The questionnaire had three parts. The first part includes socio-demographic factors (age, marital status, residence, family size, education, occupation, and others). The second part was dietary-related information questionnaires which were adapted and modified from the Food and Agriculture Organization of the United Nations (FAO) 2016 [36]. The dietary diversity questioner has ten different food groups based on their nutrients:1) grains, white root, tubers, and plantains, 2) pulses (beans, peas, and lentils), 3) nuts and seeds, 4) dairy, 5) meat and fish (poultry and fish), 6) eggs, 7) dark green leafy vegetables, 8) vitamin A-rich fruits and vegetables, 9) others vegetables, and 10) others fruits. It was assessed by using 24-h open dietary recall methods; one point was given to each food group consumed over the past $24 \mathrm{~h}$ before the survey period. The participants were asked about all food and beverage consumed during the day and night including any snack in the past 24 $\mathrm{h}$ and the interviewer were probing for any food types forgotten by participants. Each food or beverage that the respondent mentions was circled underlined on a predefined list. The foods not included on the predefined list were classify by the principal investigator on an existing predefined food group or recorded in a separate place on the questionnaire and coded and organized later into one of the predefined food groups [36].

The third part was household food security status which was assessed by using Household Food Insecurity Access Scale (HFIAS) [37]. The household food security was categorized as food insecure for those who score 2 and above out of 27 household food insecurity indicators and while food secures categorized for pregnant women who scored less than 2 out of 27 household food insecurity indicators.

Nutritional status of pregnant women was assessed by using mid-upper arm circumference (MUAC) which was measured halfway between the olecranon process and acromion process by using -non-stretchable tape to the nearest $0.1 \mathrm{~cm}$. Nutritional status was defined as MUAC less than $22 \mathrm{~cm}$ were undernutrition and while $22 \mathrm{~cm}$ or more was considered to be normal nutritional status [38, 39].

\section{Data quality control}

Initially, a survey questionnaire was prepared in English translated to the local language and translated back to English to check for consistency. A three days training was given for data collectors and supervisors and a pretest was done on $5 \%$ of the study sample size. The Cronbach's alpha was calculated $(P=0.78)$. The data were checked by the principal investigator on the daily basis for completeness and consistency. 


\section{Data processing and analysis}

After the data were cleaned and coded, the data were entered in Epidata 3.1 version software and exported to statistical package for social science (SPSS) version 21 for analysis. A minimum dietary diversity score (MDDS) was dichotomized as meet minimum dietary diversity for pregnant women who consumed 5 and above out of ten food groups coded as 1 and while unmeet minimum dietary diversity for those who consume less than 5 out of ten food groups in the past $24 \mathrm{~h}$ coded as 0. Descriptive analysis was done to calculate the mean, frequencies, and percentage distributions for the variables. A stepwise backward elimination logistic regression was done to identify variables associated with minimum dietary diversity. The model fitness was checked by using Hosmer and Lemeshow statistic $(P=0.47)$, which showed the model was fitted. Bivariate logistic regression was done to identify the covariate associated with minimum dietary diversity and independents variables and the variables with a $p$-value less than 0.05 were considered for multivariable logistic regression to control all possible confounders and to determine the strength of association between minimum dietary diversity and each explanatory variable. The strength of association was measured with an adjusted odds ratio (AOR) with a 95\% CI. Finally, the variables with a $P$-value less than 0.05 were considered statistically significant.

\section{Result}

Socio-demographic and other related characteristics of pregnant women at Wacha primary hospital, Southwest Ethiopia, $2021(N=263)$

A total of 274 respondents were participated in this study making a response rate of $96 \%$. The mean $( \pm$ Standard deviation(SD)) age of the respondents was 26.2 $( \pm 5.48)$ years and more than half of $(52.1 \%)$ women were in the age group of $<25$ years. Nearly half of the respondents $(47.5 \%)$ were protestant religion followers, and the majority of participants (96.2\%) were married. Around $32.3 \%$ of pregnant women were attended primary school by their educational status. Regarding the occupation $53.2 \%$ of pregnant women were housewives, and the majority of $(76.4 \%)$ pregnant women were Kaffa in ethnicity and greater than half $(59.7 \%)$ of the respondents were urban residents. About $64.3 \%$ of participants had a family size of $<5$; and while $73.4 \%$ of pregnant women's households heads were husbands. The majority of (97.7\%) of pregnant women were free from any illness for the past 2 weeks before the data collection and more than half (66.6\%) of pregnant women were food insecurity. Around $30.8 \%$ (95\%CI: $25.1,36.5)$ of pregnant women were undernourished and while the large majority (69.2, 95\% CI: 63.5, 74.9) were had normal nutritional status (Table 1).
Food consumption patterns of pregnant women at Wacha primary hospital, Southwest Ethiopia, 2021 ( $N=$ 263)

Regarding the food groups consumed by pregnant women in the previous $24 \mathrm{~h}$, about $98.5 \%$ consumed starchy stable food groups, $75.3 \%$ consumed pulses, food groups, $56.3 \%$ were consumed dark green leafy vegetables and 51\% were consumed other vitamin -A-rich fruits and vegetables and while the least consumed food groups were eggs $(8.7 \%)$ and meat and fish $(11.8 \%)$ (Fig. 1).

\section{Maternal minimum dietary diversity among pregnant women at Wacha primary hospital, Southwest Ethiopia, 2021, $(N=263)$}

According to this study, out of the 10 food groups that the mean dietary diversity score among pregnant women was $4.5 \pm 1.268$ SD with scores ranging from 1 to 8 food groups. About 51\% (95\% CI: 44.5, 56.7) of pregnant women meet the minimum dietary diversity scores, and while around 49\% (95\% CI: 43.3, 55.5) were consumed less than five food groups (unmeet minimum dietary diversity score).

\section{Factors associated with minimum dietary diversity}

In bi-variable logistic regression analysis the variables; women occupation being employee, nutrition awareness, head of household being husband, age of women fewer than 25 and age between 25 to 34 years and age of husbands 26 to 34 years were significantly associated ( $P$ value less than 0.05 ) with the minimum dietary diversity score. In multivariable logistic regression analysis, the variables; the age of women fewer than 25 and age between 25 to 34 years, age of husbands between 26 to 34 years and age group 35 to 44 years, and maternal nutritional awareness were significantly associated with minimum dietary diversity score. The pregnant women with the age group of fewer than 25 years were 4.64 times more likely (AOR $=4.65 ; 95 \% \mathrm{CI} ; 1.404,15.396)$ and in the age group of 25 to 34 years were 3.62 times more likely (AOR $=3.624 ; 95 \%$ CI: $1.315,10.269)$ to have minimum dietary diversity score compared with than those who had aged greater than 34 years. Women having husbands age group 26 to 34 years were 2.2 times more likely $(\mathrm{AOR}=2.238 ; 95 \% \mathrm{CI} ; 1.028,4.873)$ and age group 35 to 44 years were 3.555 times more likely (AOR = $3.555 ; 95 \% \mathrm{CI} ; 1.228,10.292$ ) to have minimum dietary diversity score than those who having husband age group between 19 to 25 years olds. The pregnant women who received nutrition information during pregnancy were 2.2 times more likely ( $\mathrm{AOR}=2.182 ; 95 \% \mathrm{CI} ; 1.243$, 3.829 ) to meet minimum dietary diversity score than those who didn't get nutrition information (Table 2). 
Table 1 Socio-demographic characteristics of pregnant women at Wacha primary hospital, Southwest Ethiopia, 2021 (N=263)

\begin{tabular}{|c|c|c|c|}
\hline Variables & & Frequency & Percentage \\
\hline \multirow[t]{3}{*}{ Age of women } & $<25$ & 137 & $52.1 \%$ \\
\hline & $25-34$ & 97 & $36.9 \%$ \\
\hline & $>34$ & 29 & $11.0 \%$ \\
\hline \multirow[t]{3}{*}{ Age of husband } & $19-25$ & 45 & $17.1 \%$ \\
\hline & $26-34$ & 134 & $51 \%$ \\
\hline & $35-44$ & 84 & $31.9 \%$ \\
\hline \multirow[t]{4}{*}{ Marital status } & Married & 253 & $96.2 \%$ \\
\hline & Single & 5 & $1.9 \%$ \\
\hline & Widowed & 2 & $0.8 \%$ \\
\hline & Divorced & 3 & $1.1 \%$ \\
\hline \multirow[t]{4}{*}{ Women religion } & Orthodox & 113 & $43 \%$ \\
\hline & Protestant & 125 & $47.5 \%$ \\
\hline & Muslim & 20 & $7.6 \%$ \\
\hline & Other * & 5 & $1.9 \%$ \\
\hline \multirow[t]{2}{*}{ Residence } & Urban & 157 & $59.7 \%$ \\
\hline & Rural & 106 & $40.3 \%$ \\
\hline \multirow[t]{3}{*}{ Ethnicity } & Kaffa & 201 & $76.4 \%$ \\
\hline & Amhara & 39 & $14.8 \%$ \\
\hline & Other** & 23 & $8.8 \%$ \\
\hline \multirow[t]{5}{*}{ women education } & Unable to read and write & 77 & $29.3 \%$ \\
\hline & Able to read and write & 12 & $4.6 \%$ \\
\hline & primary & 85 & $32.3 \%$ \\
\hline & secondary & 43 & $16.3 \%$ \\
\hline & college and above & 46 & $17.5 \%$ \\
\hline \multirow[t]{5}{*}{ husband educational } & Unable to read and write & 62 & $23.6 \%$ \\
\hline & Read and write & 9 & $3.4 \%$ \\
\hline & Primary (1-8) & 65 & $24.7 \%$ \\
\hline & Secondary (9-12) & 75 & $28.5 \%$ \\
\hline & College and above & 52 & $19.8 \%$ \\
\hline \multirow[t]{4}{*}{ Women occupational } & Housewife & 140 & $53.2 \%$ \\
\hline & Government employee & 52 & $19.8 \%$ \\
\hline & Merchant & 34 & $12.9 \%$ \\
\hline & Daily labor & 37 & $14.1 \%$ \\
\hline \multirow[t]{3}{*}{ Head of household } & Husband & 193 & $73.4 \%$ \\
\hline & Wife & 25 & $9.5 \%$ \\
\hline & Both & 45 & $17.1 \%$ \\
\hline \multirow[t]{2}{*}{ Family size } & $<5$ & 169 & $64.3 \%$ \\
\hline & $>=5$ & 94 & $35.8 \%$ \\
\hline \multirow[t]{2}{*}{ Income } & $<=1500$ & 123 & $46.8 \%$ \\
\hline & $>1500$ & 140 & $53.2 \%$ \\
\hline \multirow[t]{3}{*}{ Shopping } & Wife & 240 & $91.3 \%$ \\
\hline & Husband & 21 & $8 \%$ \\
\hline & Other & 2 & $0.8 \%$ \\
\hline Nutrition awareness & Yes & 158 & $60.1 \%$ \\
\hline
\end{tabular}


Table 1 Socio-demographic characteristics of pregnant women at Wacha primary hospital, Southwest Ethiopia, 2021 (N=263) (Continued)

\begin{tabular}{|c|c|c|c|}
\hline Variables & & Frequency & Percentage \\
\hline & No & 105 & $39.9 \%$ \\
\hline \multirow[t]{2}{*}{ Husband support } & Yes & 244 & $92.8 \%$ \\
\hline & No & 19 & $7.2 \%$ \\
\hline \multirow[t]{2}{*}{ Bank account } & Yes & 99 & $37.6 \%$ \\
\hline & No & 164 & $62.4 \%$ \\
\hline \multirow[t]{2}{*}{ Mobile } & Yes & 145 & $55.1 \%$ \\
\hline & No & 118 & $44.9 \%$ \\
\hline \multirow[t]{2}{*}{ Radio } & Yes & 156 & $59.3 \%$ \\
\hline & No & 107 & $40.7 \%$ \\
\hline \multirow[t]{2}{*}{ Garden } & Yes & 184 & $70 \%$ \\
\hline & No & 79 & $30 \%$ \\
\hline \multirow[t]{2}{*}{ Fasting } & Yes & 84 & $31.9 \%$ \\
\hline & No & 179 & $68.1 \%$ \\
\hline \multirow[t]{2}{*}{ Latrine } & Yes & 262 & $99.6 \%$ \\
\hline & No & 1 & $0.4 \%$ \\
\hline \multirow[t]{3}{*}{ Water source } & Tap & 47 & $17.9 \%$ \\
\hline & Spring & 170 & $64.6 \%$ \\
\hline & Well & 46 & $17.5 \%$ \\
\hline \multirow[t]{2}{*}{ Illness } & Yes & 6 & 2.3 \\
\hline & No & 257 & $97.7 \%$ \\
\hline \multirow[t]{2}{*}{ Food security status } & $<2$ & 175 & $66.6 \%$ \\
\hline & $\geq 2$ & 88 & $33.4 \%$ \\
\hline \multirow[t]{2}{*}{ Nutritional status } & $<22$ & 81 & $30.8 \%$ \\
\hline & $\geq 22$ & 182 & $69.2 \%$ \\
\hline
\end{tabular}

Notes: $\mathrm{N}=$ total number of participants, * Catholic, Pagan, ${ }^{* *}$ Bench, Oromo, Wolayita, Tigre, Selte

\section{Discussion}

Minimum dietary diversity of pregnant women

This study was aimed to assess the minimum dietary diversity and associated factors among pregnant women attending ANC at Wacha primary hospital, Southwest Ethiopia. According to this study finding around 51\% of pregnant women had met a minimum dietary diversity which is lower than the study finding from Burkina Faso (68.4\%) [30], Addis Ababa (60.9\%) [40], Hosanna town of Ethiopia (75.8\%) [41], and Alamata (61.2\%) [2]; and while higher than the national level of Ethiopia (47\%) [27], SNNPR region of Ethiopia (28\%) [23], East Gojjam Zone of Northwest Ethiopia (45\%) [42], Jille Tumuga (31.4\%) [32], Bale (44.8\%) [33], Dire Daw city (43\%) [39] and Shashemene town (25.4\%) [43]. The possible explanation for this prevalence discrepancy might be due to study periods differences, geographical differences, socio-cultural differences, and differences in the measurement of dietary diversity which some study uses nine food groups and while other studies used the 14 food groups, and those consumed four or more food groups of the fourteen food groups were classified as minimum dietary diversity which will result in a greater score than this finding.

\section{Food groups consumption patterns of pregnant women} In this study about 98.5 and $75.3 \%$ of pregnant women consumed grain, white roots, tuber, and plantains food groups (pasta, taro, enset, potato; teff, wheat, maize, rice in the form of injera, bread, porridge) and pulse food groups (beans, peas, and lentils) respectively and while the least consumed food groups were eggs (8.7\%), meat, poultry and fish food groups (11.8\%), other fruits (16.7\%) and dairy food groups (17.9\%) in the previous $24 \mathrm{~h}$. it is consistent with the others study findings from Kenya [31], Hossana Town of southern Ethiopia [41], SNNPR of Ethiopia [25], and Bale zone of southeast Ethiopia [33]. Moreover, it is consistent with many others studies finding from developing countries where their main dietary sources are cereal-based food groups [44]. But there is a slight difference from the study conducted in the East Gojjam zone where the commonly 


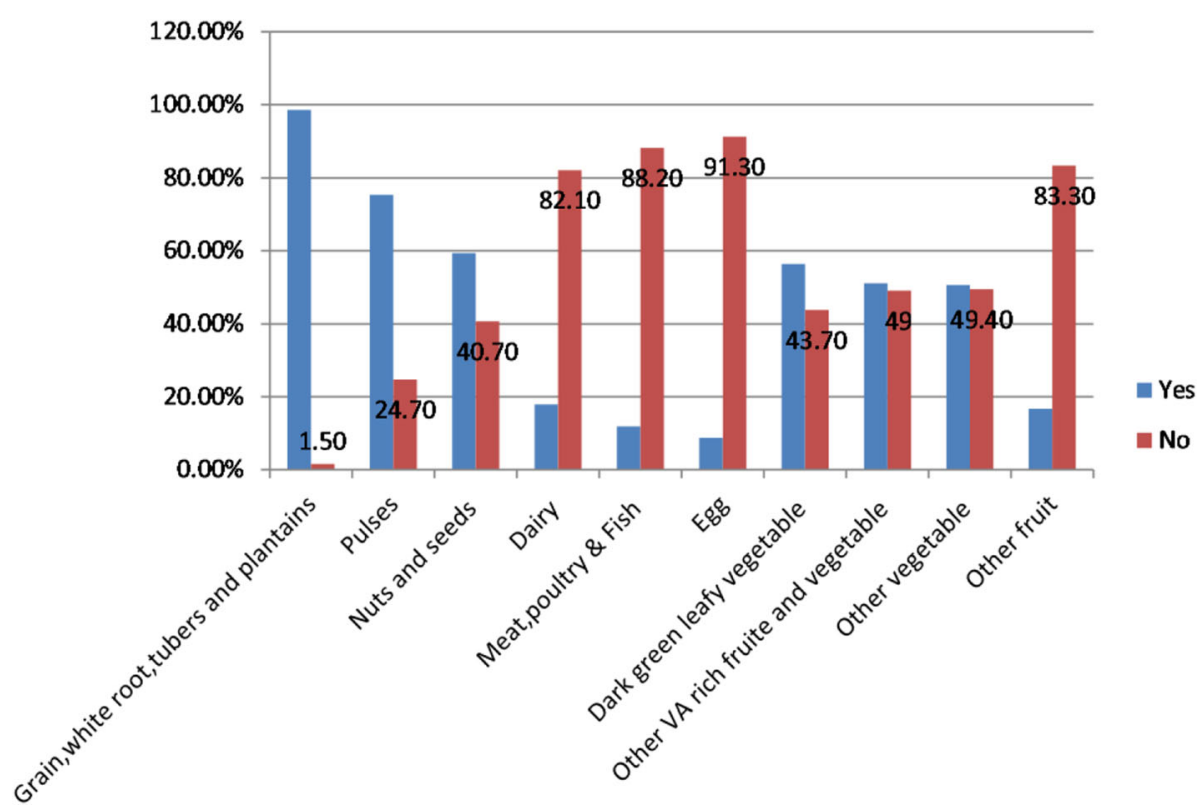

Fig. 1 Food group's consumption patterns of pregnant women at Wacha primary hospital, Southwest Ethiopia 2021

consumed dietary groups were legumes, nuts, and seeds (85.5\%) followed by starchy staples (64.7\%) [42]. This finding was also inconsistent with the study finding from the SNNPR regional state of Ethiopia where $71 \%$ vs.56.3\% of pregnant women were consumed vitamin Arich dark green leafy vegetables and $19 \%$ vs. $51 \%$ of pregnant women were consumed other vitamin A-rich fruits and vegetables food groups [25]. This inconsistency finding could happen due to seasonal variation, self- reporting differences, and the measurement difference of dietary diversity.

\section{Factors associated with minimum dietary diversity of pregnant women}

The pregnant women with the age group of fewer than 25 years were 4.65 times more likely to attain the minimum dietary diversity score than those with the age group greater than 34 years old. This could be due to

Table 2 Factors associated with minimum dietary diversity at Wacha primary Hospital, Southwest Ethiopia, $2021(\mathrm{~N}=263)$

\begin{tabular}{|c|c|c|c|c|c|}
\hline \multirow[t]{2}{*}{ Variable } & & \multicolumn{2}{|c|}{ Dietary diversity } & \multirow[t]{2}{*}{ COR $(95 \% \mathrm{Cl})$} & \multirow[t]{2}{*}{ AOR $(95 \% \mathrm{Cl})$} \\
\hline & & Poor & Good & & \\
\hline \multirow[t]{3}{*}{ Age of women } & $<25$ & 65 & 72 & $2.460(1.047,5.789)$ & $4.65(1.404,15.396)^{*}$ \\
\hline & $25-34$ & 45 & 52 & $2.57(1.063,6.204)$ & $3.62(1.315,10.269)^{*}$ \\
\hline & $>34$ & 20 & 9 & 1 & 1 \\
\hline \multirow[t]{3}{*}{ Age of husband } & $19-25$ & 29 & 16 & 1 & 1 \\
\hline & $26-34$ & 60 & 74 & $2.24(1.111,4.497)$ & $2.24(1.028,4.873)^{*}$ \\
\hline & $35-44$ & 41 & 43 & $1.90(0.902,4.006)$ & $3.55(1.228,10.292)^{*}$ \\
\hline \multirow[t]{4}{*}{ Occupation of women } & Housewives & 63 & 77 & 1 & 1 \\
\hline & Employee & 32 & 20 & $0.510(0.267,0.980)^{*}$ & $0.61(0.268,1.383)$ \\
\hline & Merchant & 17 & 17 & $0.39(0.386,1.732)$ & $0.90(0.408,2.135)$ \\
\hline & Daily laborer & 18 & 19 & $0.864(0.418,1.732)$ & $1.310(0.555,3.091)$ \\
\hline \multirow[t]{3}{*}{ House hold head } & Husband & 89 & 104 & $2.12(1.081,4.151)^{*}$ & $1.049(0.406,2.706)$ \\
\hline & Wife & 12 & 13 & $1.964(0.727,5.386)$ & $0.598(0.261,1.371)$ \\
\hline & Both & 29 & 16 & 1 & 1 \\
\hline \multirow[t]{2}{*}{ Nutrition awareness } & Yes & 70 & 88 & $1.676(1.019,2.758)$ & $2.182(1.243,3.829)^{*}$ \\
\hline & No & 60 & 45 & 1 & 1 \\
\hline
\end{tabular}


the younger pregnant women might know that the double burden of malnutrition during younger age so that they might be trying to have adequate dietary diversity during their pregnancy. Pregnant women with the age group of 25 to 34 years were 3.624 times more likely to have the minimum dietary diversity score than those with the age group greater than 34 years. This finding is consistent with the study conducted in Eat Gojjam zone where maternal age was significantly associated with the dietary diversity of pregnant women in bi-variable logistic regression as the age of the mother increases the likelihood of inadequate dietary diversity was increased [42]. This might indicate that as the women age becomes old their access to get adequate dietary diversity might become poor.

The pregnant women with their husband's age group is 26 to 34 years old were 2.20 times more likely to have minimum dietary diversity than those with their husband age group is 19 to 25 years olds. Besides, the pregnant women with their husband's age group are 35 to 44 years were 3.56 times more likely to have minimum dietary diversity than those with their husband age group were 19 to 25 years olds. The possible explanation for this could be because the women who have older age husbands might support the pregnant women to have adequate dietary diversity during pregnancy than the women who have younger age husbands.

The pregnant women who had received nutrition awareness during pregnancy were 2.182 times more likely to have a minimum dietary diversity score than those who had not received nutrition awareness during pregnancy. This finding is consistent with the finding from Ethiopia where lack of counseling about dietary diversity was one of the factors significantly associated with inadequate dietary diversity in Ethiopia [27]. It is also consistent with the study conducted in Addis Ababa where having nutritional information during pregnancy was significantly associated with minimum dietary diversity [40].

This study cannot make the causal relationship (difficult to know which precedes the exposure or outcome). Hence, it is a cross-sectional study. The study is unable to generalize to the population because of the facilitybased nature of this study. In addition, this study might not give the exact figure of the dietary diversity practice due to a recall bias and is self-reported. A relatively small sample size of this study might be the other limitation.

\section{Conclusion}

This study has shown that the overall consumption of adequate dietary diversity of pregnant mothers was found low. The variables like women of age fewer than 25 and age between 25 to 34 years, husbands age between 26 to 34 and 35 to 44 years, and maternal nutrition awareness were positively significantly associated with adequate dietary diversity of pregnant mothers at Wacha primary hospitals. Therefore, providing nutrition education and counseling services is warranted to promote maternal dietary diversity. Moreover, other researchers should conduct further study to see the association of husbands ages between 26 to 34 and 35 to 44 years and mothers ages fewer than 25 and age between 25 to 34 years with minimum dietary diversity during pregnancy. Encourage pregnant mothers to improve their dietary diversity by increasing the daily consumption of food groups like animals source foods and different types of fruits.

\section{Abbreviations}

ANC: Antenatal Care; AOR: Adjusted Odds Ratio; Cl: Confidence Interval; FAO: Food and Agriculture Organization; FANTA: Food and Nutrition Technical Assistance; HFIAS: Household Food Insecurity Access Scale; MDDS: Minimum Dietary Diversity Score; MUAC: Mid upper arm circumference; SD: Standard Deviation; SNNPR: South Nation, Nationality and People Region; SPSS: Statistical Package for Social Science; WHO: World Health Organization

\section{Acknowledgments}

We are grateful to Research Directorate Office, Mizan-Tepi University, for the grants. We want to thank Wacha primary hospital administration and ANC clinic staff for their marvelous collaboration. Finally, we want to thank data collectors, supervisors, and all women who participated in this research.

\section{Authors' contributions}

AGT wrote the proposal, participated in data collection, conception, study design, execution, acquisition of data, analysis, and interpretation, and was a major contributor in preparing the manuscript. AMK approved the proposal with some revisions, participated in data analysis, and revised subsequent drafts of the paper commented on the final paper and manuscript. All authors read and approved the final manuscript.

\section{Funding}

Mizan- Tepi University provided financial support for this study. The University provided the research thematic area and call for a proposal. The university research and community support directorate monitored and evaluated initially the proposal until finalization and presentation of the research findings.

\section{Availability of data and materials}

The datasets used and or analyzed during the current study are available from the corresponding author on reasonable request.

\section{Declarations}

\section{Ethics approval and consent to participate}

This study was conducted following the Declaration of Helsinki. Ethical clearance was obtained from Mizan-Tepi University research and community support offices. Before this survey, a formal letter was submitted to heads of the respective zonal health offices and each selected health facility. The study's objective, benefit, and risks were explained to the participants before data collection and obtained written informed consent from all respondents. The study participants were assured of the attainment of confidentiality, and the information they give us will not be used for any purpose other than the study.

Consent for publication

Not applicable.

Competing interests

The authors declare that they have no competing interests. 
Received: 24 April 2021 Accepted: 24 September 2021

Published online: 28 October 2021

\section{References}

1. Arimond, M., L. E. Torheim, D. Wiesmann, M. Joseph, and A. Carriquiry., Dietary Diversity as a Measure of Women's Diet Quality in Resource-Poor Areas: Results from rural Bangladesh site:Washington, DC: Food and Nutrition Technical Assistance (FANTA) Project/Academy for Educational Development (AED), March, 2008.

2. Jemal K, Awol M. Minimum dietary diversity score and associated factors among pregnant women at Alamata general hospital, Raya Azebo zone, Tigray region, Ethiopia. Journal of nutrition and metabolism. 2019;2019:1-6. https://doi.org/10.1155/2019/8314359.

3. Arsenault JE, Nikiema L, Allemand P, Ayassou KA, Lanou H, Moursi M, et al. Seasonal differences in food and nutrient intakes among young children and their mothers in rural Burkina Faso. Journal of nutritional science. 2014; 3:e55. https://doi.org/10.1017/jns.2014.53.

4. King JC. Physiology of pregnancy and nutrient metabolism. Am J Clin Nutr. 2000;71(5):1218S-25S. https://doi.org/10.1093/ajcn/71.5.1218s

5. Engidaye $\mathrm{G}$, et al. Under nutrition, maternal anemia and household food insecurity are risk factors of anemia among preschool aged children in Menz Gera Midir district, eastern Amhara, Ethiopia: a community based cross-sectional study. BMC Public Health. 2019;19(1):1-11.

6. Sonko A. Assessment of dietary practice and anthropometric status of pregnant women in Aleta Chuko Woreda southern nations, nationalities and People's region/SNNPR/. Ethiopia J Epidemiol Public Health Rev. 2016; 1(1):1-9.

7. Wangalwa G, et al. Effectiveness of Kenya's Community Health Strategy in delivering community-based maternal and newborn health care in Busia County, Kenya: non-randomized pre-test post test study. The Pan African Medical Journal. 2012;13(Suppl 1).

8. Ely DM, Driscoll AK. Infant mortality in the United States, 2017: data from the period linked birth/infant death file; 2019.

9. Keflie TS, et al. Dietary patterns and risk of micronutrient deficiencies: their implication for nutritional intervention in Ethiopia. J Nutrit Health Food Sci. 2018;6(1):1-16. https://doi.org/10.15226/jnhfs.2018.001120.

10. Daba G, Beyene F, Garoma W, Fekadu H. Assessment of knowledge of pregnant mothers on maternal nutrition and associated factors in Guto Gida Woreda, east Wollega zone, Ethiopia. J Nutr Food Sci. 2013;3(6):1 https://doi.org/10.4314/star.v2i3.98748

11. Tolera, B., S. Mideksa, and N. Dida, ASSESSMENT OF DIETARY PRACTICE AND ASSOCIATED FACTORS AMONG PREGNANT MOTHER IN AMBO DISTRICT, WEST SHOA, OROMIA, ETHIOPIA, 2018. Ethiopian Journal of Reproductive Health, 2018. 10(4).

12. Zerfu TA, Pinto E, Baye K. Consumption of dairy, fruits and dark green leafy vegetables is associated with lower risk of adverse pregnancy outcomes (APO): a prospective cohort study in rural Ethiopia. Nutrition \& diabetes. 2018:8(1):1-7. https://doi.org/10.1038/s41387-018-0060-y.

13. Zerfu TA, Umeta M, Baye K. Dietary diversity during pregnancy is associated with reduced risk of maternal anemia, preterm delivery, and low birth weight in a prospective cohort study in rural Ethiopia. Am J Clin Nutr. 2016; 103(6):1482-8. https://doi.org/10.3945/ajcn.115.116798.

14. Forouzanfar $\mathrm{MH}$, Alexander $\mathrm{L}$, Anderson HR, Bachman VF, Biryukov S, Brauer $M$, et al. Global, regional, and national comparative risk assessment of 79 behavioural, environmental and occupational, and metabolic risks or clusters of risks in 188 countries, 1990-2013: a systematic analysis for the Global Burden of Disease Study 2013. The Lancet. 2015;386(10010):2287323.

15. Desyibelew HD, Dadi AF. Burden and determinants of malnutrition among pregnant women in Africa: a systematic review and meta-analysis. PLoS One. 2019;14(9):e0221712. https://doi.org/10.1371/journal.pone.0221712.

16. Zerfu TA, Biadgilign S. Pregnant mothers have limited knowledge and poor dietary diversity practices, but favorable attitude towards nutritional recommendations in rural Ethiopia: evidence from community-based study. BMC nutrition. 2018;4(1):1-9. https://doi.org/10.1186/s40795-018-0251-x.

17. Weldehaweria NB, et al. Dietary diversity and related factors among lactating women visiting public health facilities in Aksum town, Tigray. Northern Ethiopia BMC Nutrition. 2016;2(1):1-9.

18. Lartey A. Maternal and child nutrition in sub-Saharan Africa: challenges and interventions. Proc Nutr Soc. 2008;67(1):105-8. https://doi.org/10.1017/S002 9665108006083
19. Smith ER, Shankar AH, Wu LSF, Aboud S, Adu-Afarwuah S, Ali H, et al. Modifiers of the effect of maternal multiple micronutrient supplementation on stillbirth, birth outcomes, and infant mortality: a meta-analysis of individual patient data from 17 randomised trials in low-income and middle-income countries. Lancet Glob Health. 2017;5(11):e1090-100. https:// doi.org/10.1016/S2214-109X(17)30371-6.

20. International Food Policy Research Institute. Global Nutrition Report 2016: From Promise to Impact: Ending Malnutrition by 2030. Washington, D.C.; 2016. http://dx.doi.org/10.2499/9780896295841.

21. Lee SE, Talegawkar SA, Merialdi M, Caulfield LE. Dietary intakes of women during pregnancy in low-and middle-income countries. Public Health Nutr. 2013;16(8):1340-53. https://doi.org/10.1017/\$1368980012004417.

22. Baer HJ, Blum RE, Rockett HRH, Leppert J, Gardner JD, Suitor CW, et al. Use of a food frequency questionnaire in American Indian and Caucasian pregnant women: a validation study. BMC Public Health. 2005:5(1):1-11. https://doi.org/10.1186/1471-2458-5-135.

23. (IFPRI), T.I.F.P.R.I., Nutrition Interventions in Antenatal Care and Immediate Postnatal Care FINDINGS FROM A BASELINE SURVEY IN ETHIOPIA. 2019.

24. EDHS, C.S.a., Ethiopia demographic and health survey 2016: key indicators report.. 2016.

25. Hirvonen and Wolle's Consumption, Production, Market Access and Affordability of Nutritious Foods in the SNNP Region of Ethiopia. 2019 report, : Addis Ababa:International Food Policy Research Institute (IFPRI) and Alive\&Thrive/FHI360

26. Misganaw A, et al. National mortality burden due to communicable, noncommunicable, and other diseases in Ethiopia, 1990-2015: findings from the global burden of disease study 2015. Popul Health Metrics. 2017;15(1): $1-17$.

27. Hidru HD, Berwo Mengesha M, Hailesilassie Y, Tekulu Welay F. Burden and determinant of inadequate dietary diversity among pregnant women in Ethiopia: a systematic review and Meta-analysis. Journal of Nutrition and Metabolism. 2020;2020:1-10. https://doi.org/10.1155/2020/1272393.

28. Biradar KB. Assessment of nutritional supplements prescribed in pregnant women and pediatric patients in Basaveshwara teaching and general hospital. J Food Nutr. 2015;1:1-9.

29. Sukchan $P$, Liabsuetrakul T, Chongsuvivatwong V, Songwathana $P$, Sornsrivichai $V$, Kuning M. Inadequacy of nutrients intake among pregnant women in the deep south of Thailand. BMC Public Health. 2010;10(1):1-8. https://doi.org/10.1186/1471-2458-10-572.

30. Savy M, Martin-Prével Y, Traissac P, Eymard-Duvernay S, Delpeuch F. Dietary diversity scores and nutritional status of women change during the seasonal food shortage in rural Burkina Faso. J Nutr. 2006;136(10):2625-32. https://doi.org/10.1093/jn/136.10.2625.

31. Kiboi, W., J. Kimiywe, and P. Chege, Dietary diversity, nutrient intake and nutritional status among pregnant women in Laikipia County, Kenya. International Journal of Health Sciences \& Research, 2016: p. 378-379.

32. Aliwo S, Fentie M, Awoke T, Gizaw Z. Dietary diversity practice and associated factors among pregnant women in north East Ethiopia. BMC research notes. 2019:12(1):1-6. https://doi.org/10.1186/s13104-019-4159-6.

33. Hailu S, Woldemichael B. Dietary diversity and associated factors among pregnant women attending antenatal care at public health facilities in bale zone. Southeast Ethiopia Nutrition and Dietary Supplements. 2019;11:1-8. https://doi.org/10.2147/NDS.S179265.

34. Workicho A, Belachew T, Feyissa GT, Wondafrash B, Lachat C, Verstraeten R, et al. Household dietary diversity and animal source food consumption in Ethiopia: evidence from the 2011 welfare monitoring survey. BMC Public Health. 2016;16(1):1-11. https://doi.org/10.1186/s12889-016-3861-8.

35. Ali., f., assessment of dietary diversity and nutritional status of pregnant women in malaysia. journal of ayub medical college, 2014. 26(4).

36. FAO , F., Minimum dietary diversity for Womens: a guidelines to measurement,. 2016

37. Deitchler M, B.T., Swindale A, Coates J.. , Validation of a measure of household hunger for cross-cultural use, in Acedemy for Educational Development. 2010 Jun 8.: Washington, DC:

38. Belete Y, N.B.a.F.M., Under Nutrition and Associated Factors among Adolescent PregnantWomen in Shashemenne District, West Arsi Zone, Ethiopia: A Communitybased Study. Nutrition \& Food Sciences, 2016. 6(1).

39. Shenka A, et al. Dietary diversity and nutritional status of pregnant women attending public hospitals in Dire Dawa city administration, eastern Ethiopia. East African Journal of Health and Biomedical Sciences. 2018;2(1): $10-7$. 
40. Tefera W, Brhanie TW, Dereje M. Dietary diversity practice and associated factors among pregnant women attending ANC in Kolfe Keranyo sub city health centers. Ethiopia. medRxiv: Addis Ababa; 2020.

41. Delil R, T.D., Zinab B. , Dietary diversity and its association with anemia among pregnant women attending public health facilities in South Ethiopia. Ethiopian journal of health sciences. , 2018; 28(5).

42. Yeneabat T, et al. Maternal dietary diversity and micronutrient adequacy during pregnancy and related factors in east Gojjam zone, Northwest Ethiopia, 2016. BMC pregnancy and childbirth. 2019;19(1):1-9.

43. Desta M, Akibu M, Tadese M, Tesfaye M. Dietary diversity and associated factors among pregnant women attending antenatal clinic in Shashemane, Oromia, Central Ethiopia: a cross-sectional study. Journal of nutrition and metabolism. 2019;2019:1-7. https://doi.org/10.1155/2019/3916864.

44. Saaka M, O.J., Larbi A, Hoeschle-Zeledon I.. . Dietary diversity is not associated with haematological status of pregnant women resident in rural areas of northern Ghana. J nutrition and metabolism., 2017.

\section{Publisher's Note}

Springer Nature remains neutral with regard to jurisdictional claims in published maps and institutional affiliations.

Ready to submit your research? Choose BMC and benefit from:

- fast, convenient online submission

- thorough peer review by experienced researchers in your field

- rapid publication on acceptance

- support for research data, including large and complex data types

- gold Open Access which fosters wider collaboration and increased citations

- maximum visibility for your research: over $100 \mathrm{M}$ website views per year

At BMC, research is always in progress.

Learn more biomedcentral.com/submissions 